\title{
Effects of Process Parameter Variation on the Bonding Strength in Clad Steel Strips by Twin-Roll Strip Casting
}

\author{
Dennis Münster ${ }^{1, a^{*}}$, Michele Vidoni ${ }^{1, b}$ and Gerhard Hirt ${ }^{1, c}$ \\ ${ }^{1}$ Institute of Metal Forming, RWTH Aachen University, Intzestraße 10, 52056 Aachen, Germany

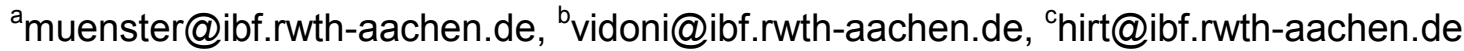

Keywords: Twin-roll strip casting, clad strip, composite materials, new processes.

\begin{abstract}
Twin-roll strip casting represents a promising alternative production route for clad steel strips. The main idea behind the presented research is the introduction of a prefabricated strip into the melt pool of a twin-roll casting process to exploit the heat of the melt to create bonding between the cast strip and the prefabricated strip. Prior investigations [1] proved the general feasibility of this concept for steel-steel combinations and described the bonding of the two layers. This concept is now further investigated with the aim to understand the influence of the process parameters on the bonding. For the experiments an austenitic high manganese steel is cladded with an austenitic stainless steel. Beginning from a starting point determined in numerical simulations, a process window for the introduction of a $0.3 \mathrm{~mm}$ thick strip of 1.4301 was identified by process parameter variation during casting experiments. Up to $25 \mathrm{~m}$ long clad strips with a thickness ratio between cast strip and inserted strip ranging from 6:1 to 10:1 were produced this way. Micrographic examinations of the clad strips' cross sections were carried out to describe the influence of the casting parameters on the joining interface. Higher element diffusion was found in clad strips with larger thickness ratios, indicating a stronger bonding of the two layers. Afterwards the observations from the micrographic examination were compared to the results of bonding strength which were obtained by a customised shear test. In support of the findings of the micrographic examinations the average bonding strength rose from around $100 \mathrm{MPa}$ for a ratio of $7: 1$ to over $300 \mathrm{MPa}$ for the ratio of 10:1. Although the process parameters with the main influence on the bonding strength, the contact time and the thickness ratio, have been identified more research is needed to quantify their influence.
\end{abstract}

\section{Introduction}

With technological advances the requirements of materials in engineering applications are increasing. This leads to a rapidly increasing interest in clad products since clad metals combine material properties of two or more metals or alloys in a way which is either very costly or even impossible to obtain with a single material.

Current industrial production routes for clad flat products mainly include cold and hot rolling, explosion cladding or deposition welding. A complete overview of production methods for clad metals is given by Liu et al. [2]. These established methods possess certain short comings. For roll cladding the combinations are limited by the flow behaviour of the materials [3], while the main disadvantages for explosion cladding are low productivity, delicate handling and the negative environmental impact of the process.

Twin-roll strip casting is a continuous casting process which produces a metallic sheet directly from the melt. This minimises the need for substantial secondary processing as it is necessary for products made by conventional continuous casting processes. After first being described by Sir Henry Bessemer in 1865 [4], extensive research was necessary for the process to become a standard practice in the aluminium industry [5] and its industrial introduction in the steel industry [6,7].

Exploiting the advantages of direct strip casting for the production of clad materials has been the subject of several studies. Haga et al. [8] have proposed several setups to produce clad strips of different aluminium alloys directly from the melt. Bae et al. [9] used a different approach by inserting prefabricated aluminium strips into the twin-roll casting process of magnesium. This 
concept has been further investigated by Grydin et al. [10] with the insertion of a steel strip into an aluminium casting process. However all these processes have been performed at small laboratory scales with casting roll diameters smaller than $400 \mathrm{~mm}$ and with relatively low melting temperatures at below $700{ }^{\circ} \mathrm{C}$.

The general feasibility of the approach of inserting a prefabricated strip into the melt pool, as illustrated in Fig. 1 (a), for steel pairings has been proven [1]. The focus of the presented research is to evaluate how the process parameters influence the bonding quality. Numerical simulations are carried out to examine the temperature development in the melt pool and to derive a promising process window for the casting experiments. Afterwards metallographic examinations are carried out to describe the joining interface while the joining strength is characterised by mechanical testing.

(a)

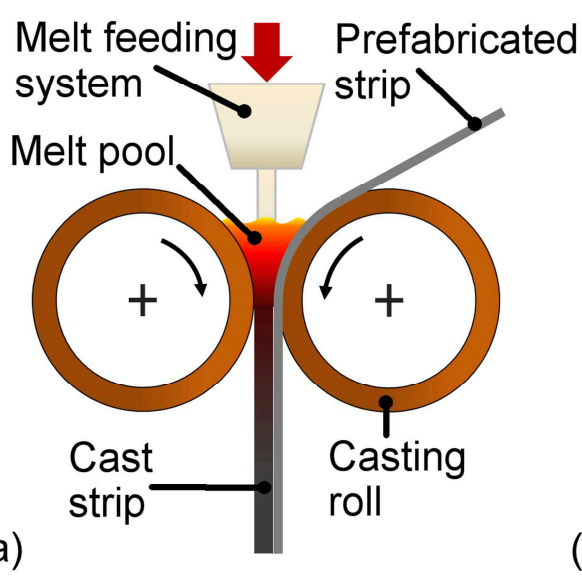

(b)

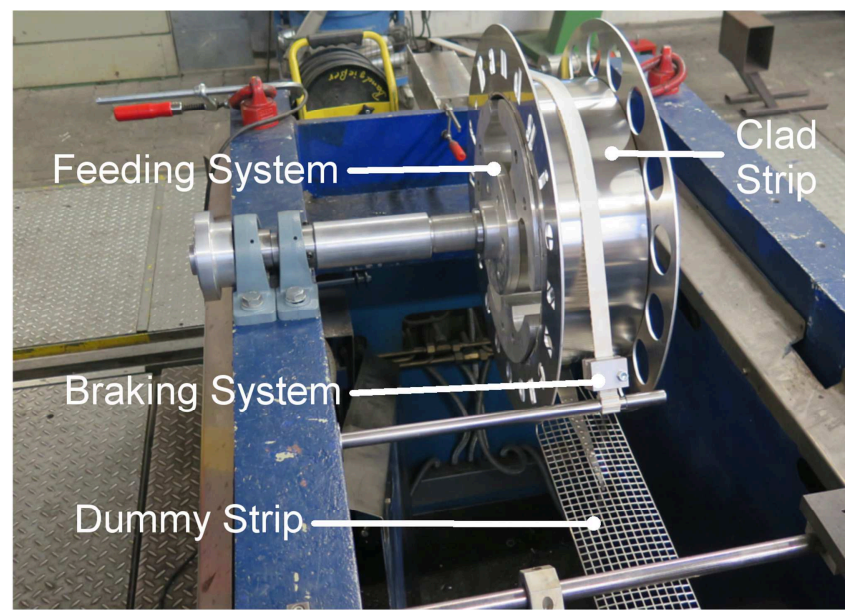

Figure 1: (a) Depiction of the casting principle, (b) Feeding system prepared for the experiment

\section{Methods}

Experimental Setup. The Institute of Metal Forming (IBF), in cooperation with ThyssenKrupp Steel Europe AG, operates a laboratory size vertical twin-roll strip caster which is able to reproduce the whole industrial process route for hot-strips. The twin-roll caster is equipped with an induction furnace and two water-cooled copper casting rolls with a diameter of $580 \mathrm{~mm}$ and a width of $150 \mathrm{~mm}$. It is possible to cast strips within the thickness range of 0.8 to $3.0 \mathrm{~mm}$ with a roll separation force of up to $50 \mathrm{kN}$ on the machine. Furthermore it includes an in-line hot rolling mill and two optional cooling zones.

For the experiments a feeding system for the prefabricated strip is installed (see Fig. 1 (b)). The prefabricated strip is coiled onto the feeding device. It is then connected to the dummy strip which guides the prefabricated strip laterally into the pool. During the process the feeding system keeps the prefabricated strip on track. A mechanical brake applies a braking force to the feeding system, creating a tension on the inserted strip and the needed contact pressure between casting roll and inserted strip. For the experiments the braking force was set from $200 \mathrm{~N}$ to $400 \mathrm{~N}$ to examine the influence of the contact pressure. Further parameter variation includes the thickness relation between prefabricated strip and cast strip and subsequently the roll gap, and the roll separation force in order to vary the casting speed. This variation directly influences the contact time and the pool height.

In this work a high manganese steel $(\mathrm{Fe} 17 \mathrm{Mn} 0.6 \mathrm{C} 1.5 \mathrm{Al})$ is cladded with an austenitic stainless steel strip. The high manganese steel is chosen for its attractive mechanical properties [11] and its vulnerability to corrosion. The common 1.4301 (X5CrNi18-10) is selected as cladding material.

A $30 \mathrm{~m}$ long stainless steel strip with a thickness of $0.3 \mathrm{~mm}$ and a width of $80 \mathrm{~mm}$ is inserted during the experiments. Earlier experiments showed that contact between the inserted strip and the side dams leads to process instabilities with incomplete bonding. Therefore a narrow strip width allows for a big safety gap between the inserted strip and the side dams since the feeding system is 
not yet automated and no adjustment of the alignment of the inserted strip during the experiment is possible at the momentary stage.

Numerical Model. Since the temperature development in the melt pool is impossible to measure a numerical model is used to predict the shell growth of the cast strip. The numerical model is based on the principle of the moving observer. A two-dimensional plane is fixed onto the casting roll coordinate system and rotates from the point the melt first touches the casting rolls until the roll gap. The model describes the growth of the solidifying shells in this time window. A more detailed description can be found in [12]. The two different cases, melt in contact with a casting roll and melt in contact with the prefabricated strip, are solved individually. Temperatures at the interfaces and the shell growth are examined and compared. The heat transfer coefficient is varied between $\alpha=4-12 \mathrm{~kW} /\left(\mathrm{m}^{2} \mathrm{~K}\right)$ for the contact melt/roll, between $\alpha=40-50 \mathrm{~kW} /\left(\mathrm{m}^{2} \mathrm{~K}\right)$ for the contact melt/strip and between $\alpha=4-7 \mathrm{~kW} /\left(\mathrm{m}^{2} \mathrm{~K}\right)$ for the contact strip/roll to emulate the influence of the roll separation force and is kept constant throughout the simulation. More details are given in [1]. For the simulations thicknesses of $0.3 \mathrm{~mm}$ and $0.5 \mathrm{~mm}$ for the inserted strip are used to examine the influence of different heat capacities.

Clad Strip Characterisation. The joining interface is characterised by micrographic observation of the clad strip cross section. Three classifications are used to describe the interface: flat (irregularities in the joining surface are lower than $5 \mu \mathrm{m}$ (see Fig. 2 (a)), wavy (irregularities exceed $5 \mu \mathrm{m}$ (see Fig. 2 (b)) and defect (identified joining defects). The percentage of wavy irregularities is determined in samples taken from the centre and the edges of the cladded part of the

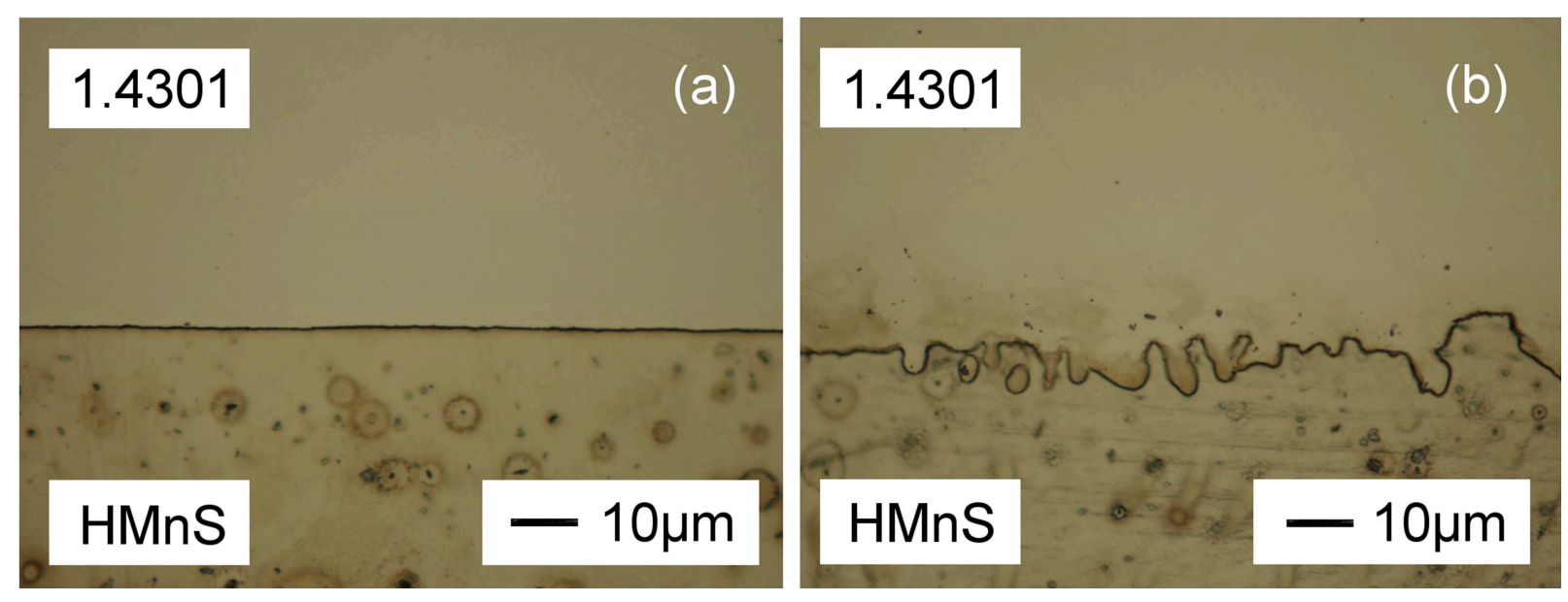

Figure 2: Microscopic images of the interface between the two steel alloys; (a) flat interface, (b) wavy interface

strip with a length ranging from 20 to $25 \mathrm{~mm}$. Since the wavy interface is an indication for good element diffusion [13], an increase of the percentage of wavy interface is aspired in the experiments. For comparability a customised shear test method by Vidoni [13] is used to quantitatively measure the bonding strength. The obtained results are matched to the micrographic observations to determine any kind of correlation between the bonding strength of clad strip and the diffusion process.

\section{Results and Discussion}

Results of the Simulation. With help of the simulation results, cooling curves are created. The example in Fig. 3 shows the temperature development of the melt for different distances from the interface at the inserted strip. Typical for it is the fast cooling of the melt in close proximity of the inserted strip's surface followed by a temperature rise due to the heating of the inserted strip. This trend continues until equilibrium is reached and the temperature difference at the interface between solidified shell and inserted strip is constant and the temperature at the interface starts decreasing again. With the help of these cooling curves the solidification law (see Eq. 1) is derived. Due to the asymmetrical cooling conditions it takes the form of 


$$
t \approx \delta_{s}+\delta_{r}=c_{s} \cdot \Delta t_{k}^{n_{s}}+c_{r} \cdot \Delta t_{k}^{n_{r}}
$$

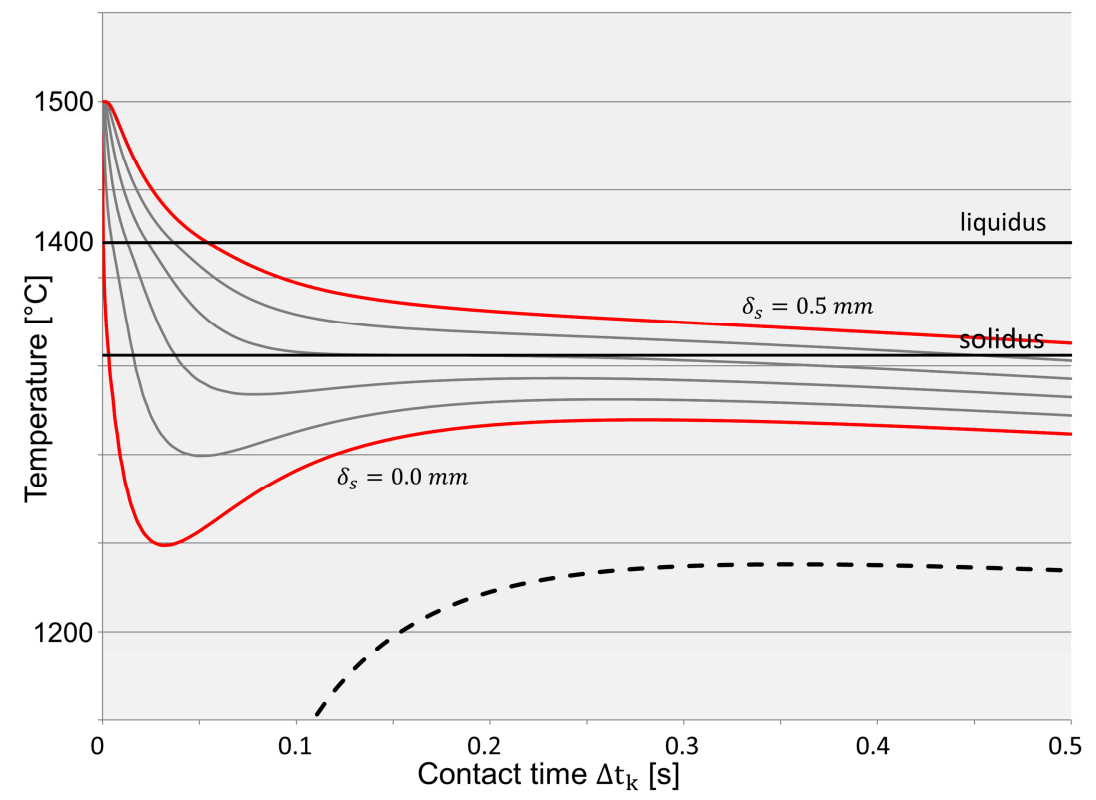

Figure 3: Exemplary cooling curves of the melt in contact with a $0.3 \mathrm{~mm}$ thick strip. $\boldsymbol{\delta}_{\boldsymbol{s}}$ gives the distance from the surface of the inserted strip. The dashed line shows the temperature development at the surface of the inserted strip at the interface with $\mathrm{t}$ being the cast strip thickness, $\delta$ the solidified shell thickness, $\Delta t_{k}$ the contact time, c and $\mathrm{n}$ are constants depending on material and process parameters, and the indices $s$ and $r$ stand for the corresponding contact situation, melt-inserted strip or melt-casting roll.

To extract promising process parameters from the simulation results the following consideration is taken into account. When equilibrium is reached, the reheating of the inserted strip reaches its highest temperature during the process and the contact time should last at least this long to guarantee a successful bonding. With this contact time and Eq. 1 a cast strip thickness can be determined. For the chosen thickness of $0.3 \mathrm{~mm}$ for the inserted strip and a demanded contact time of roughly $0.4 \mathrm{~s}$, the thickness ratio of between cast strip and inserted strip of $6: 1\left(\Delta t_{k}=0.44 \mathrm{~s}\right)$, resulting in a total thickness of the clad strip of $2.1 \mathrm{~mm}$, is chosen as a starting parameter. With the contact time and the casting roll geometry the casting speed for the experiments is calculated and controlled via the roll separation force in the experiment.

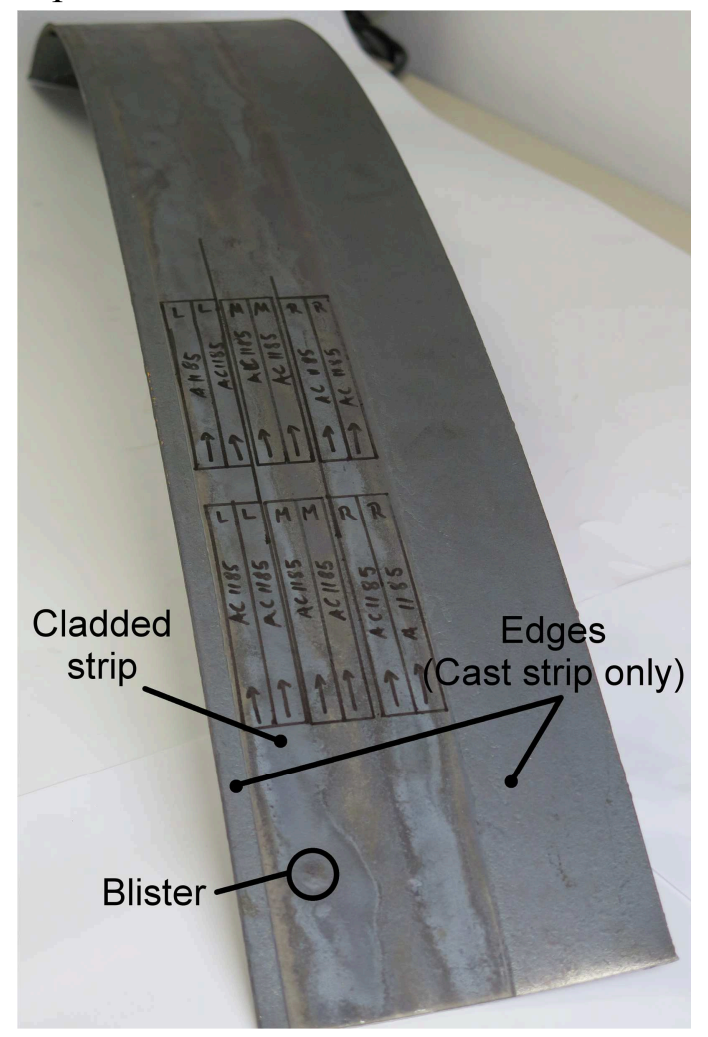

Figure 4: Section of the cladded strip during sample preparation
Results from the Casting Experiments. After a startup period of about 4-5 meters the remaining length of the inserted strip joined with the cast strip nearly defect free. A close examination revealed only occasional blisters for clad strips with thickness ratios from 6:1 up to 10:1 but no cases of delamination existed (see Fig. 4). A stable process was achieved with roll separation forces (RSFs) ranging from 35 to $50 \mathrm{kN}$. Higher RSFs were needed with smaller ratios to achieve longer contact times. To ensure a good contact between inserted strip and casting roll a breaking force of at least $400 \mathrm{~N}$ was needed. Additionally a high melt pool and therefore a high hydrostatic pressure onto the inserted strip proved to be favourable.

For thickness ratios smaller than $6: 1$ only incomplete bonding was achieved. Due to the rapid solidification at initial contact, a high RSF was reached within a short contact time. The small contact area resulted in insufficient heating of the inserted strip. The inserted strip warped and led to unpredictable contact conditions between inserted strip and melt. As a consequence melt flowed between the casting roll and the inserted strip resulting in strong fluctuations in the RSF. This prevented the force speed control of the caster from 


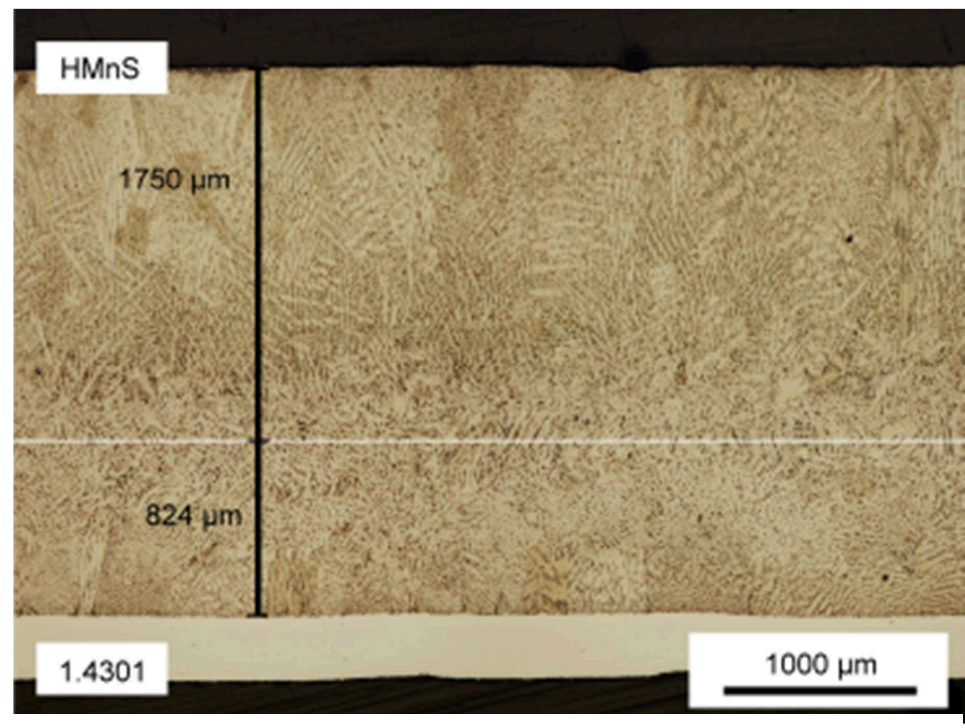

Figure 5: Microscopic image of the cross section showing the asymmetrical shell growth

reaching a stable operating point. Thus a stable melt pool did not develop for these ratios during the start-up period. An insertion of the prefabricated strip after the start-up phase once a stable process is reached and an even higher RSF might solve this problem and expand the process window.

Microstructure. Images of the cross section of the clad strips are taken with an optical microscope (see Fig. 5). The asymmetrical shell growth of the cast strip is clearly visible in these images and the thickness of the shells is measured to validate the predicted shell growth from the simulation results. Furthermore the interface of four random samples for each of the thickness ratios 7:1, 8:1, 9:1 and 10:1 are examined and their average percentage of wavy interfaces (see Fig. 2 (b)) compared. Despite the low sample number and high statistical dispersion a general tendency towards higher percentages for thicker cast strips is visible (see Fig. 6). The highest mean value $(57 \%)$ and the highest absolute value (78\%) are recorded for the thickness ratio of 10:1. The contact time for the segment from which the samples are taken is the longest with nearly $0.5 \mathrm{~s}$. But for a higher significance more samples have to be examined.

Mechanical Testing. Shear tests were performed on 30 samples with the shear length $l_{s}=1 \mathrm{~mm}$. 18 of the 30 samples failed through shearing, in the case of the other 12 samples the 1.4301 strip failed. The distribution of the samples and the number of sheared samples are given in Table 1 . Also shown in Table 1 are the arithmetic mean, the maxima and the minima of the measured shear stress for the different ratios.

Table 1: Overview of the measured shear stress and sample size for the different thickness ratios.

\begin{tabular}{|l|c|c|c|c|c|}
\hline Ratio & Samples & Sheared & Arithmetic mean [MPa] & Maximum [MPa] & Minimum [MPa] \\
\hline $7: 1$ & 9 & 8 & 118 & 307 & 61 \\
\hline $8: 1$ & 9 & 5 & 178 & 373 & 70 \\
\hline $9: 1$ & 6 & 3 & 231 & 487 & 68 \\
\hline $10: 1$ & 6 & 2 & 15 & 14 & 16 \\
\hline
\end{tabular}

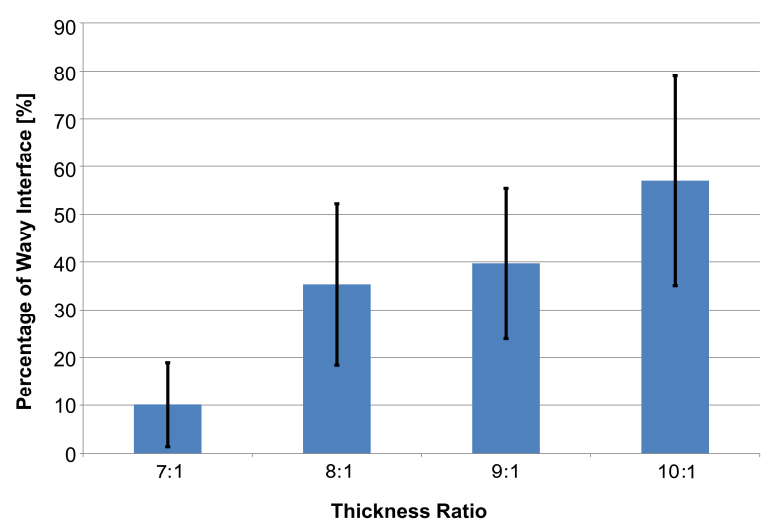

Figure 6: Arithmetic mean and standard deviation of the measured percentage of wavy interface for different thickness ratios
Comparing the arithmetic mean of the measured stress for the thickness ratios $7: 1,8: 1$ and $9: 1$ the trend of the micrographic observation is supported. The strength of the bonding rises with the rising percentage of the wavy interface and therefore the element diffusion.

Only two samples of the ratio 10:1 sheared. The measured stress for these samples is so low they most likely have been damaged during their manufacturing. In the case of the failure of the 1.4301 strip for this ratio, the measured stress represents the strength of material of the inserted strip. Since the material failed before the bonding the actual strength of the bonding 
for these samples is higher. The measured average for these samples of roughly $300 \mathrm{MPa}$ gives an idea of the actual bonding strength.

Although a trend is visible, to produce more reliable figures more samples have to be examined to minimise the influence of stochastic irregularities in the bonding. Due to dimensions of the inserted strip the shearing area is relatively small, resulting in a rather strong influence of these irregularities on the measured stress.

\section{Conclusion}

A production process for clad steel strips by twin-roll casting developed at the IBF was further investigated with a focus on the pairing of a stainless steel with a high manganese steel. Numerical simulations and casting experiments were carried out to improve the process parameters in order to strengthen the bonding between the two layers. A process window was identified and the produced clad strip examined with regard to the influence of the process parameters on the bonding strength and the element diffusion. These are mainly influenced by two process parameters, the thickness ratio between inserted strip and cast strip, and the contact time. The larger the ratio and the longer the contact time the better the bonding strength is the general trend although further research is needed to better quantify the influence.

\section{Acknowledgements}

The authors gratefully acknowledge the financial support of the "Deutsche Forschungsgemeinschaft" (DFG) within the project "Dünnbandgießen zur Herstellung plattierter Stahlbänder Zweirollen-Gießplattieren" (Hi790/50-1). The authors would like to thank ThyssenKrupp Steel Europe AG for their good collaboration and financial support.

\section{References}

[1] M. Vidoni, M. Daamen, G. Hirt, Numerical and Experimental Investigation of a Modified Twin Roll Strip Casting Process for the Production of Clad Steel Strips. Key Engineering Materials (2015)

[2] L. Li, F.X. Yin, K. Nagai, Progress of laminated materials and clad steels production, Material Science Forum 675 (2011) 439-447.

[3] M. Bambach, M. Pietryga, A. Mikloweit, G. Hirt, A finite element framework for the evolution of bond strength in joining-by-forming processes, Journal of Materials Processing Technology 214.10 (2014) 2156-2168

[4] H. Bessemer, Improvement in the manufacture of malleable iron and steel, U.S. Patent No. $51401(1865)$

[5] B.Q. Li, Producing Thing Strips by Twin-Roll Casting - Part I: Process Aspects and Quality Issues, JOM 47.5 (1995): 29-33

[6] H.U. Lindenberg, U. Albrecht-Fruh, M. Walter, R. Capotosti, G. Stebner, D. Senk, ForumTechnische Mitteilungen Thyssen Krupp (English Edition), (2000)

[7] D.J. Sosinsky, P. Campbell, R, Mahapatra, W. Blejde, F. Fisher, The CASTRIP ${ }^{\circledR}$ processrecent developments at Nucor Steel's commercial strip casting plant, Metallurgist, 52.11-12 (2008) 691-699.

[8] T. Haga, R. Nakamura, S. Kumai, H. Watari, Clad strip casting by a twin roll caster, Archives of Materials Science and Engineering, 37.2 (2009) 117-124

[9] J.H. Bae, A.P. Rao, K.H. Kim, N.J. Kim, Cladding of Mg alloy with Al by twin-roll casting, Scripta Materialia, 64.9 (2011), 836-839 
[10] O. Grydin, G. Gerstein, F. Nürnberger, M. Schaper, V. Danchenko, Twin-roll casting of aluminum-steel clad strips, Journal of Manufacturing Processes 15.4 (2013) 501-507

[11]B.C. de Cooman, O. Kwon, K.G. Chin, State-of-the-knowledge on TWIP steel, Materials Science and Technology 28.5 (2012) 513-527

[12] M. Daamen, T. Förster, G. Hirt, Experimental and Numerical Investigation of Double Roller Casting of Strip with Profiled Cross Section, Steel Research Special Edition ICTP (2011) 93-97

[13] M. Vidoni, R. Ackermann, S. Richter, G. Hirt, Production of Clad Steel Strips by Twin-Roll Strip Casting, Advanced Engineering Materials (2015) 